\title{
Effect of session order in combined aerobic and resistance training on glycemic control in older adults with type 2 diabetes: a crossover study
}

\author{
Efeito da ordem da sessão de treinamento aeróbio e resistido no controle glicêmico \\ em idosos com diabetes tipo 2: um estudo cruzado
}

\begin{tabular}{l} 
AUTHOR'S \\
\hline Renato Ferreira Corrêa $^{1}$ (D) \\
João Guilherme Vieira $^{2}$ (DD \\
Marcelo Ricardo Diass,2 (D) \\
1 Granbery Methodist College, Laboratory of \\
Exercise Physiology and Morphofunctional \\
Assessment, Juiz de Fora, Minas Gerais, Brazil. \\
2. Federal University of Juiz de Fora, Postgraduate \\
Program in Physical Education, Juiz de Fora, Brazil.
\end{tabular}

\section{CORRESPONDING}

Marcelo Ricardo Dias

diasmr@gmail.com

Rua Floriano Peixoto, 937 / 503, Juiz de Fora, Minas Gerais, Brazil.

CEP: $36015-440$.

\section{DOI}

$10.12820 /$ rbafs.26e0222

\begin{abstract}
The session order of aerobic and resistance training seems to be important for glycemic behavior, as when performed in isolation they help to reduce glycosylated hemoglobin. The purpose of the present study was to compare the acute effect of aerobic and resistance training session orders on glycemia levels of older adults with type 2 diabetes mellitus. A counterbalanced crossover design was used in this study. Eighteen older adults with type 2 diabetes, 13 men and 5 women, non-insulin and beta-blocker dependents, were recruited. All participants performed two training sessions in different orders: aerobic + resistance (AER) and resistance + aerobic (RES). There was a seven-day interval between sessions. In the AER session, a significant $(p<0.001)$ decrease in blood glucose was observed between training (Mid moment: $p<0.001$ ) and after each session (Post moment: $p=$ 0.003) compared to the baseline (Pre moment). In the RES session, no difference ( $p=0.731$ ) was found at the Mid moment in relation to the Pre moment, but a significant $(p<0.001)$ decrease in blood glucose was observed in the Post moment. A comparison of the different training sessions showed a significant difference $(p=0.012)$ at the Mid moment, whereas the blood glucose showed a sharper reduction the AER session. In conclusion, we observed that combined training, regardless of the order, was effective for acute glycemic behavior in older people with type 2 diabetes, and aerobic training was the main factor responsible for the reduction blood glucose.
\end{abstract}

Keywords: Blood glucose; Diabetes mellitus; Endurance training; Strength training.

RESUMO

A ordem da sessão de treino aeróbio e resistido parece ser importante para a resposta glicêmica, uma vez que quando realizados isoladamente ajudam a reduzir a hemoglobina glicosilada. O objetivo do presente estudo foi comparar a ordem da sessão de treinamento aeróbio e resistido na resposta glicêmica agudo em idosos com diabetes tipo 2. A amostra foi composta por idosos, diagnosticados com diabetes do tipo 2, 13 homens e 5 mulheres, não tratados com insulina e betabloqueadores. Todos realizaram duas sessöes de treinamentos com diferentes ordens: aeróbio + resistido (AER) e resistido + aeróbio (RES). As sessóes foram separadas por sete dias. Na sessão AER, foi observado uma diminuição significativa $(p<0,001)$ da glicemia entre as sessões (ENTRE: $p<0,001$ ) e após cada sessão (PÓS: $p=0,003$ ) em comparação com a linha de base (PRÉ). Na sessão RES, nenbuma diferença $(p>0,731)$ foi encontrada no momento ENTRE em relação ao momento $P R E$, mas uma diminuição significativa $(p<0,001)$ da glicose no sangue foi observada no momento PÓS. Uma comparação das diferentes sessões de treinamento mostrou uma diferença significativa $(p=0,012)$ no momento ENTRE, enquanto a glicemia mostrou uma queda mais acentuada na sessão AER. Concluiu-se que o treinamento combinado, independente da ordem, foi eficaz na resposta glicêmica aguda em idosos com diabetes do tipo 2 e o treinamento aeróbico foi o principal responsável pela queda de glicose no sangue.

Palavras-chave: Glicose sanguínea; Diabetes mellitus; Treino aeróbio; Treinamento de força.

\section{Introduction}

Diabetes mellitus is a major public health problem in many countries, affecting millions of people, with the prospect of a $50 \%$ increase by 2040 . Type 2 diabetes mellitus accounts for $90-95 \%$ of cases of diabetes mellitus, of which physical inactivity and advancing age are some of the risk factors ${ }^{1}$. Exercise is one of the pillars of treatment for diabetes, fighting physical inactivity, which in turn has a significant impact on the improvement of glycemic control ${ }^{2}$. Aerobic and resistance training is recommended as an important non-pharmacological strategy for glycemic control in older adults with diabetes mellitus ${ }^{3}$.

Studies have shown that aerobic training is effective 
in improving glycemic control ${ }^{4,5}$. The American College of Sports Medicine and the American Diabetes Association ${ }^{6}$ recommend that older adults with type 2 diabetes perform aerobic training at least three days a week, with an intensity of $40-60 \%$ of maximal $\mathrm{VO}_{2}$ and a minimum duration of ten minutes per session, totaling approximately 150 minutes per week. Regarding resistance training, Castaneda et al. ${ }^{7}$ suggested that increasing muscle strength can improve blood glucose control. In addition, resistance training improves insulin sensitivity in older adults with type 2 diabetes mellitus ${ }^{8}$. For such, the training program should be prescribed in five to ten exercises for large muscle groups for at least two non-consecutive days a week. One to three sets of ten to fifteen repetitions with moderate (50\% 1RM) or heavy intensity (75-80\% 1RM) are indicated ${ }^{6}$.

In skeletal muscle, both aerobic and resistance training lead to increased expression of the muscle glucose transporter type 4 (GLUT-4), but resistance training presented higher possibilities of muscle mass gain and, thus, increased glucose storage capacity, ${ }^{9}$. Therefore, aerobic and resistance training, when performed in isolation, play a relevant role in the glycemic control of older adults with type 2 diabetes mellitus. A combination of aerobic and resistance training has been recommended by several international organizations ${ }^{3,11,12}$. Increase in muscle mass from resistance training can contribute to blood glucose uptake without altering the ability of muscle to respond to insulin. On the other hand, aerobic exercise improves blood glucose uptake through increased insulin action, independent of changes in muscle mass ${ }^{13}$. Associating aerobic with resistance training (i.e., combined training) seems to be even more effective for glycemic behavior, as it helps to reduce glycosylated hemoglobin ${ }^{8,10,14}$. Nevertheless, the order of sessions of combined training remains poorly understood. The present study aimed to compare the acute effect of the order of sessions combining aerobic and resistance training on the glycemia of older adults with type 2 diabetes mellitus. Our hypothesis was that the combination of aerobic and resistance training, regardless of order, will lower blood glucose, and that the largest decreases in each session will occur after aerobic training.

\section{Methods}

The sample consisted of eighteen older adults, 13 men and 5 women, participating in a Cardiopulmonary and Metabolic Rehabilitation program. The entire sample presented diabetes mellitus type 2 and was on oral an- tidiabetic agents. To participate in the survey, all were required to have been attending the program for at least three months and be familiar with the exercises proposed. The use of insulin and beta-blocker drugs was adopted as an exclusion criterion. The use of alpha-blocker, anti-diabetic, cholesterol and triglyceride, diuretic, diabetes mellitus control (except insulin), angiotensin receptor, and vasodilator drugs were permitted. During the research, participants were not required to control their diet, for the results of this study to reflect the actual daily lives of the participants. After agreeing to participate in the research, the subjects signed an informed consent form, and all procedures were conducted in accordance with the ethical standards of the Declaration of Helsinki (1964) and approved by a local Research Ethics Committee (protocol number: 4.076.498).

A counterbalanced crossover design was used in this study, which was conducted over three visits. At the first visit, anthropometric measurements were taken, and the subjects were familiarized with the training. At the second and third visits, they were randomly assigned to counterbalance input in two training sessions with different execution orders: (I) aerobic followed by resistance (AER) and (II) resistance followed by aerobic (RES). A period of five minutes between training and seven days between sessions was respected. In both sessions, the subjects initially performed a warm-up, which consisted of five minutes of gentle walking with increasing treadmill speed every minute until the training heart rate (HR) was reached, for the AER session; and a specific warm-up in the first exercise with the same number of repetitions used in training (10 repetitions) with a light load (a score of up to 5 on the OMNI-RES scale) for the RES session. All training sessions were supervised by the researchers in this study, who have experience in aerobic and resistance training, and assisted in load adjustments, as well as in the follow-up of training sessions.

A treadmill walk (LX160i, Movement ${ }^{\circledR}$, Brazil) was performed for 30 continuous minutes with an intensity of $50 \%$ of the heart rate reserve. For such, resting $\mathrm{HR}$ was measured before the beginning of training, in which the individual remained at rest for five minutes. The maximum heart rate $\left(\mathrm{HR}_{\max }\right)$ was calculated using the formula proposed by Tanaka et al. ${ }^{15}: \mathrm{HR}_{\max }=208$ - $(0.7 \mathrm{x}$ age $)$. During training, HR was measured every two minutes with a heart rate monitor (FS2, Polar ${ }^{\circledR}$, Finland) and the researcher kept track of the HR by increasing or decreasing the treadmill speed. 
Resistance training was performed for approximately 30 minute, with five exercises: seated bench press, free dumbbell squat, seated cable row, standing plantar flexion, and lateral dumbbell lift. The bench press and low row exercises were performed in a multifunctional station (MS400 Multi-Station, Riguetto ${ }^{\circledR}$, Brazil). All subjects performed three sets of ten repetitions with moderately difficult intensity, i.e., a score of 5 to 7 on the OMNI-RES scale ${ }^{16}$. The interval between sets was one minute.

Capillary blood glucose was collected using a glucometer (Freestyle OptiumNeo H, Abbott ${ }^{\circledR}$, USA) that quantifies plasma glucose. For this measurement, a drop of blood was collected from the ear lobe of the subjects and subsequently deposited on a disposable biosensor tape coupled to the glucometer. The collection was performed by an experienced and qualified professional five minutes before the training session (Pre), between training (Mid), and five minutes after each session (Post).

To calculate the inferential statistics of the data, the probability distribution function was tested by the Shapiro-Wilk test, and homoscedasticity, by the Levene test. A t-test for independent measurements was performed to verify the difference between individual data (age, body mass, height, and BMI) among men and women. To compare blood glucose in both sessions, we used a two-way analysis of variance (ANOVA) (sessions: AER and RES) with repeated measures (moment: Pre, Mid and Post), followed by Tukey Post hoc test to identify the differences. For such, the sphericity of the variables was verified by the Mauchly test. Considering the total sample size $(\mathrm{n}=18)$, a post hoc analysis with the $G^{*}$ Power 3.0 software ${ }^{17}$ indicated a 95\% statistical power, requiring a minimum effect size of 0.4. The $f^{2}$ Cohen ES was conducted for verify the magnitude of the differences between training sessions with the magnitude classified as small $(\geq 0.20-\leq$ $0.60)$, moderate $(\geq 0.60-\leq 1.20)$, or large $(\geq 1.20)^{18}$. The significance level was 5\%, and the software used for data analysis was GraphPad (Prism 8.0.1, San Diego, CA, USA).

\section{Results}

The subjects presented a period with diagnosed diabetes mellitus of $11.40 \pm 7.29$ years and reported the use of alpha-blocker (doxazosin), anti-diabetic (alogliptin, glibenclamide, glimepiride), cholesterol and triglyceride (fenofibrate, rosuvastatin calcium, simvas- tatin), diuretic (chlorthalidone, hydrochlorothiazide), diabetes mellitus control (empagliflozin, gliclazide, metformin hydrochloride, pioglitazone hydrochloride, vildagliptin), angiotensin receptor (losartan potassium, ramipril, valsartan), and vasodilator (amlodipine besylate). The individual sample data did not show a statistical difference between men and women (Table 1). The sample was classified as overweight according to Body Mass Index - BMI (between 25.00 and 30.00 $\mathrm{kg} / \mathrm{m}^{2}$ ). Individual data values presented a coefficient of variation $<20.00 \%$. In addition, no adverse events or intolerance was observed with the training sessions (e.g. hypoglycemia).

Table 1 - Participants characteristics.

\begin{tabular}{lccc}
\hline & Men $(\mathrm{n}=13)$ & Women $(\mathrm{n}=5)$ & $\mathrm{p}$-value \\
\hline Age (years) & $66.92 \pm 8.21(12.27 \%)$ & $60.20 \pm 10.33(17.16 \%)$ & 0.239 \\
Body mass $(\mathrm{kg})$ & $78.85 \pm 13.75(17.44 \%)$ & $81.60 \pm 12.68(15.54 \%)$ & 0.698 \\
Height $(\mathrm{m})$ & $1.71 \pm 0.05(3.15 \%)$ & $1.66 \pm 0.08(4.93 \%)$ & 0.207 \\
BMI $(\mathrm{kg} / \mathrm{m} 2)$ & $26.75 \pm 4.04(15.12 \%)$ & $29.68 \pm 3.78(12.73 \%)$ & 0.185 \\
\hline
\end{tabular}

$\mathrm{BMI}=$ Body mass index; Values are expressed as mean \pm standard deviation (coefficient of variation).

The Mauchly test found a violation of sphericity for time ( $p$ < 0.001) using the Geisser-Greenhouse Epsilon and sphericity was assumed for the interaction of time $x$ session $(p=0.708)$. Two-way ANOVA showed interaction between training sessions and time $[\mathrm{F}(1.91$, $32.62)=18.26 ; \mathrm{p}<0.001]$ and effect for time $[\mathrm{F}(1.18$, $20.12)=24.62 ; \mathrm{p}<0.001]$. There was no effect for the training sessions $[\mathrm{F}(1.00,17.00)=0.27 ; \mathrm{p}=0.604]$.

Table 2 presents the ANOVA result of the repeated glycemic values at each moment and between the different training sessions. Upon comparing the different training sessions, only a significant difference was found at the Mid moment, whereas glycemia presented a sharper reduction session beginning with aerobic training. The effect size was found to be small between the sessions at the Pre and Post moments and large at the Mid moment.

In sessions beginning with aerobic training (AER), a significant reduction in blood glucose was found for Mid ( $\mathrm{p}<0.001)$ and Post $(\mathrm{p}=0.003)$ compared to Pre. In sessions beginning with resistance training (RES) no significant difference was found $(\mathrm{p}=0.731)$ at the Mid moment in relation to the Pre moment; however, a significant decrease was found $(\mathrm{p}<0.001)$ in relation to the Post moment. Table 3 shows the percentage difference results and effect size. 
Table 2 - Capillary blood glucose values between training.

\begin{tabular}{|c|c|c|c|c|}
\hline & $\operatorname{AER}(\mathrm{mg} / \mathrm{dL})$ & RES (mg/dL) & p-value & $\mathrm{ES}$ \\
\hline Pre & $138.17 \pm 32.17(122.17-154.16)$ & $137.06 \pm 42.99(115.68-158.43)$ & 0.887 & 0.03 \\
\hline Mid & $106.94 \pm 34.55 *(89.75-124.12)$ & $132.89 \pm 37.04^{\dagger}(114.47-151.30)$ & 0.012 & 1.40 \\
\hline Post & $113.83 \pm 34.93 *(96.45-131.20)$ & $101.83 \pm 32.44^{* \#}(85.69-117.96)$ & 0.234 & 0.39 \\
\hline
\end{tabular}

Values are expressed as mean \pm standard deviation (lower-upper 95\% Confidencial Interval of the mean); AER = aerobic + resistance; RES = resistance + aerobic; ES = Effect size; ${ }^{*}$ Significant difference from the Pre; \# Significant difference from the Mid; † Significant difference between training sessions.

Table 3 - Changes in blood glucose between the moments.

\begin{tabular}{lcc}
\hline & AER & RES \\
\hline Pre vs Mid & $0.93(-22.60)$ & $0.10(-3.04)$ \\
Pre vs Post & $0.72(-17.61)$ & $0.92(-25.70)$ \\
Mid vs Post & $0.19(6.44)$ & $0.89(-23.37)$ \\
\hline
\end{tabular}

Values are expressed as effect size (percentage delta); AER = aerobic + resistance; $\mathrm{RES}=$ resistance + aerobic.

\section{Discussion}

The present study aimed to compare the acute effect of session order in combined aerobic and resistance training on the glycemic behavior of older adults with type 2 diabetes mellitus. The main results showed that there were no significant differences between the orders at the end of each session, i.e., a sharp decrease in capillary blood glucose was found regardless of the order of combined training. These results corroborate with Moro et al. ${ }^{19}$, in which combined training produced positive effects on glycemic control in older adults with type 2 diabetes mellitus. These authors found that regular combined aerobic training can provide changes in metabolism capable of improving glycemic homeostasis. In this case, combined training seems to be more effective with regard to glycosylated hemoglobin control, and aerobic training, with regard to plasma glucose. Glycosylated hemoglobin allows the glycemic behavior of the last three to four months to be verified on the date of the test, analyzing possible peaks and reduction in blood glucose during this period regardless of the fasting state, while plasma glucose analyzes the glucose value acutely ${ }^{1}$.

In the present study, capillary blood glucose reduction occurred only after aerobic training, regardless of the order in which combined training was performed. According to the study by Boulé et al. ${ }^{20}$, aerobic training was able to reduce fasting insulin levels, which was accompanied by increased insulin sensitivity. The authors reported that after 72 hours, fasting insulin returned to baseline levels, and a slight increase in fasting glucose occurred 24 and 72 hours after the session. In addition to the acute effect, some studies have shown that aerobic training promoted improved glycemic control when performed within protocols with a minimum duration of eight weeks ${ }^{21-23}$.

According to the position of the American College of Sports Medicine and the American Diabetes Association $^{6}$, the acute effects of a single resistance training session on blood glucose levels and/or insulin action in older adults with type 2 diabetes are not clear. Likewise, the present study did not find differences in acute responses to resistance training. In contrast, protocols with a duration between 8 and 24 weeks showed significant results in glycemic control through glycosylated hemoglobin ${ }^{7,21,24}$. In addition to this evidence, Church et al. ${ }^{14}$ and Sigal et al. ${ }^{10}$ reported that resistance training is of great importance in glycemic control through glycosylated hemoglobin, especially when added to aerobic training. Yardley et al. ${ }^{25}$ suggest that resistance training should be performed before aerobic training as a prescription strategy to reduce the risk of hypoglycemia.

Lack of diet control may be a limiting factor in the present study. According to Carvalho et al. ${ }^{26}$, a diet composed of an adequate amount of fiber contributes to better glycemic control. However, the procedures of this study are in line with previous research from a clinical and functional perspective ${ }^{14,19,27,28}$, in addition to closely representing the participants' reality. Additionally, as the volunteers took part in a Cardiopulmonary and Metabolic Rehabilitation program, they had medical, nutritional, physiotherapeutic, and psychological follow-up. It is important to note that the present study only performed the blood glucose collection at 5 minutes after the session, which does not represent delayed changes.

In conclusion, combined training, regardless of order, was effective for acute glycemic behavior in older adults with type 2 diabetes mellitus. Aerobic training was largely responsible for glycemic behavior. In practical terms, the inclusion of aerobic training for glycemic behavior in older adults with diabetes is essential regardless of whether prescribed before or after resistance training. Maybe, the preference of the practitioners should be taken into consideration. 


\section{Conflict of interest}

The authors declare no conflict of interest.

\section{Funding}

This study was financed in part by the Coordenação de Aperfeiçoamento de Pessoal de Nível Superior - Brasil (CAPES) - Finance Code 001.

\section{Author's contributions}

Corrêa RF and Dias MR have given substantial contributions to the conception or the design of the manuscript. Dias MR and Vieira JG to acquisition, analysis and interpretation of the data. All authors have participated to drafting the manuscript, Corrêa FC, Vieira JG and Dias MR revised it critically. All authors read and approved the final version of the manuscript. All authors contributed equally to the manuscript and read and approved the final version of the manuscript.

\section{Acknowledgments}

The authors would like to thank the Unimed Juiz de Fora for its support in the present study. The authors would also like to thank each of the participants for their efforts in the training needed for the study.

\section{References}

1. Cho NH, Shaw JE, Karuranga S, Huang Y, da Rocha Fernandes JD, Ohlrogge AW, et al. IDF Diabetes Atlas: Global estimates of diabetes prevalence for 2017 and projections for 2045. Diabetes Res Clin Pract. 2018;138:271-81.

2. Nocon M, Hiemann T, Müller-Riemenschneider F, Thalau F, Roll S, Willich SN. Association of physical ac-tivity with all-cause and cardiovascular mortality: a systematic review and meta-analysis. Eur J Cardiovasc Prev Rehabil. 2008;15(3):239-46.

3. Colberg SR, Albright AL, Blissmer BJ, Braun B, ChasanTaber L, Fernhall B, et al. Exercise and type 2 dia-betes: American College of Sports Medicine and the American Diabetes Association: joint position statement. Exercise and type 2 diabetes. Med Sci Sports Exerc. 2010;42(12):2282-303.

4. Mitranun W, Deerochanawong C, Tanaka H, Suksom D. Continuous vs interval training on glycemic control and macro- and microvascular reactivity in type 2 diabetic patients. Scand J Med Sci Sports. 2014;24(2):e69-76. doi:10.1111/sms.12112.

5. Toledo FG, Menshikova EV, Ritov VB, Azuma K, Radikova $Z$, DeLany J, et al. Effects of physical activity and weight loss on skeletal muscle mitochondria and relationship with glucose control in type 2 diabetes. Dia-betes. 2007;56(8):2142-7.

6. Colberg SR, Sigal RJ, Fernhall B, Regensteiner JG, Blissmer BJ, Rubin RR, et al. Exercise and type 2 diabe-tes: the American College of Sports Medicine and the American Diabetes Association: joint position state-ment. Diabetes Care. 2010;33(12):e147-67.

7. Castaneda C, Layne JE, Munoz-Orians L, Gordon PL, Walsmith J, Foldvari M, et al. A randomized con-trolled trial of resistance exercise training to improve glycemic control in older adults with type 2 diabetes. Di-abetes Care. 2002;25(12):2335-41.
8. Pan B, Ge L, Xun YQ, Chen YJ, Gao CY, Han X, et al. Exercise training modalities in patients with type 2 diabetes mellitus: a systematic review and network meta-analysis. Int J Behav Nutr Phys Act. 2018;15(1):72.

9. Schrauwen P, van Aggel-Leijssen DP, Hul G, Wagenmakers AJ, Vidal H, Saris WH, et al. The effect of a 3-month lowintensity endurance training program on fat oxidation and acetyl-CoA carboxylase-2 expression. Diabetes. 2002;51(7):2220-6.

10. Sigal RJ, Kenny GP, Wasserman DH, Castaneda-Sceppa C. Physical activity/exercise and type 2 diabetes. Diabetes Care. 2004;27(10):2518-39. doi:10.2337/diacare.27.10.2518.

11. Hansen D, Peeters S, Zwaenepoel B, Verleyen D, Wittebrood C, Timmerman N, et al. Exercise assessment and prescription in patients with type 2 diabetes in the private and home care setting: clinical recommenda-tions from AXXON (Belgian Physical Therapy Association). Phys Ther. 2013;93(5):597-610.

12. Rydén L, Grant PJ, Anker SD, Berne C, Cosentino F, Danchin N, et al. ESC Guidelines on diabetes, pre-diabetes, and cardiovascular diseases developed in collaboration with the EASD: the Task Force on diabetes, pre-diabetes, and cardiovascular diseases of the European Society of Cardiology (ESC) and developed in col-laboration with the European Association for the Study of Diabetes (EASD). Eur Heart J. 2013;34(39):3035-87.

13. Cuff DJ, Meneilly GS, Martin A, Ignaszewski A, Tildesley HD, Frohlich JJ. Effective exercise modality to re-duce insulin resistance in women with type 2 diabetes. Diabetes Care. 2003;26(11):2977-82.

14. Church TS, Blair SN, Cocreham S, Johannsen N, Johnson W, Kramer K, et al. Effects of aerobic and re-sistance training on hemoglobin A1c levels in patients with type 2 diabetes: a randomized controlled trial. Ja-ma. 2010;304(20):2253-62.

15. Tanaka H, Monahan KD, Seals DR. Age-predicted maximal heart rate revisited. J Am Coll Cardiol. 2001;37(1):153-6.

16. Robertson RJ, Goss FL, Rutkowski J, Lenz B, Dixon C, Timmer J, et al. Concurrent validation of the OMNI perceived exertion scale for resistance exercise. Med Sci Sports Exerc. 2003;35(2):333-41.

17. Faul F, Erdfelder E, Lang A, Buchner A. G* Power 3: A flexible statistical power analysis program for the so-cial, behavioral, and biomedical sciences. Behav Res Methods. 2007;39(2):175-91.

18. Hopkins WG, Marshall SW, Batterham AM, Hanin J. Progressive statistics for studies in sports medicine and exercise science. Med Sci Sports Exerc. 2009;41(1):3-13.

19. Moro ARP, Iop RR, Silva FC, Gutierres Filho PJB. Efeito do treinamento combinado e aeróbio no controle glicêmico no diabetes tipo 2. Fisioter Mov. 2012;25(2):399-409.

20. Boulé NG, Weisnagel SJ, Lakka TA, Tremblay A, Bergman $\mathrm{RN}$, Rankinen T, et al. Effects of exercise training on glucose homeostasis: the HERITAGE Family Study. Diabetes Care. 2005;28(1):108-14.

21. Arora E, Shenoy S, Sandhu JS. Effects of resistance training on metabolic profile of adults with type 2 diabe-tes. Indian J Med Res. 2009;129(5):515-9.

22. Bacchi E, Negri C, Zanolin ME, Milanese C, Faccioli N, Trombetta M, et al. Metabolic effects of aerobic training and resistance training in type 2 diabetic subjects: a randomized controlled trial (the RAED2 study). Diabetes Care. 2012;35(4):676-82.

23. Najafipour F, Mobasseri M, Yavari A, Nadrian $H$, Aliasgarzadeh A, Mashinchi Abbasi N, et al. Effect of regular exercise training on changes in $\mathrm{HbA} 1 \mathrm{c}, \mathrm{BMI}$ and $\mathrm{VO}(2)$ max among patients with type 2 diabetes mellitus: an 8-year trial. BMJ Open Diabetes Res Care. 2017;5(1):e000414. 
24. Dunstan DW, Daly RM, Owen N, Jolley D, De Courten $\mathrm{M}$, Shaw J, et al. High-intensity resistance training improves glycemic control in older patients with type 2 diabetes. Diabetes Care. 2002;25(10):1729-36.

25. Yardley JE, Kenny GP, Perkins BA, Riddell MC, Malcolm J, Boulay P, et al. Effects of performing resistance exercise before versus after aerobic exercise on glycemia in type 1 diabetes. Diabetes Care. 2012;35(4):669-75.

26. Carvalho FS, Pimazoni Netto A, Zach P, Sachs A, Zanella MT. Importance of nutritional counseling and die-tary fiber content on glycemic control in type 2 diabetic patients under intensive educational intervention. Arq Bras Endocrinol Metabol. 2012;56(2):110-9.
27. Sigal RJ, Kenny GP, Boulé NG, Wells GA, Prud'homme $\mathrm{D}$, Fortier M, et al. Effects of aerobic training, re-sistance training, or both on glycemic control in type 2 diabetes: a randomized trial. Ann Intern Med. 2007;147(6):357-69.

28. Jorge ML, de Oliveira VN, Resende NM, Paraiso LF, Calixto A, Diniz AL, et al. The effects of aerobic, re-sistance, and combined exercise on metabolic control, inflammatory markers, adipocytokines, and muscle insu-lin signaling in patients with type 2 diabetes mellitus. Metabolism. 2011;60(9):1244-52.

\section{Quote this article as:}

Corrêa RF, Vieira JG, Dias MR. Effect of session order in combined aerobic and resistance training on glycemic control in older adults with type 2 diabetes: a crossover study. Rev Bras Ativ Fis Saúde. 2021;26:e0222. DOI: 10.12820/rbafs.26e0222 